\title{
A Comprehensive Method for Industrial Site Selection: The Macro-Location Analysis
}

\author{
Aleksandar Rikalovic, Ilija Cosic, Ruggero Donida Labati, Vincenzo Piuri
}

\begin{abstract}
Industrial site selection is a strategic decision that involves several criteria with consideration for technical, economic, social, environmental, and political issues. These criteria are generally described using a number of different indicators, expressed in quantitative and qualitative ways with some possible uncertainty. Decision making requires, therefore, appropriate tools to enable data collection, storage, analysis, fusion, and knowledge management to address this complex, multifaceted scenario. This paper presents a Comprehensive Method for Industrial Site Selection (CMISS), an innovative approach for reasoning uncertainty and efficiently finding the most suitable solution based on a set of interacting decision support systems. Experimental results show that the proposed approach provides accurate results in the region of interest, coinciding with the choices of expert analysts.
\end{abstract}

Index Terms-Fuzzy Inference Systems (FIS), Geographic Information Systems (GIS), Industrial Site Selection, MultiCriteria Decision Analysis (MCDA)

\section{INTRODUCTION}

$I^{2}$ NDUSTRIAL site selection is one of the key decisions in the process of starting, expanding, or changing the location of an industry. The industrial location problem can be represented as a selection process of potential sites in which the attempt is made to satisfy all requirements in the best possible way.

Traditionally, industrial site selection has been based almost exclusively on economic and technical criteria. Currently, a higher degree of sophistication is desired in order to also satisfy a number of social and environmental requirements, which may be enforced by legislation and government regulations. The industrial site selection process becomes, therefore, a complex multi-criteria analysis, which includes a set of criteria encompassing technical, economic, social, environmental and political issues, possibly resulting in conflicting objectives [1, $2]$.

The present-day analyst increasingly strives not only to satisfy all constraints but also to optimize various decision criteria, which may be conflicting, and to present a number of possible sites, each with specific advantages and limitations [3, 4]. Due to the complexity of the task, the industrial site selection process is divided into two phases: the selection of a macrolocation and, within this area, the selection of a micro-location [5]. The macro-location is a geographical area (typically the size of a municipality) that meets the basic requirements for

A.Rikalovic and I.Cosic are affiliated with the University of Novi Sad, Novi Sad 21000, Serbia (e-mail: a.rikalovic@uns.ac.rs; ilijac@uns.ac.rs). construction and development of the industry with minimal operating costs. The micro-location is the specific place within the macro-location that meets technical, infrastructural and working process requirements [6].

A number of decision support tools have been used to support the identification of the most suitable industrial sites, including geographic information systems (GIS) [7], multi-criteria decision analysis (MCDA) [8], and expert systems (ES) [9]. Geographic Information Systems are mainly used to collect geographically specific data and support their location-based presentation and analysis. Multi-criteria decision analysis has been extensively used to explore the space of the available solutions and to identify the optimum selection in the presence of conflicting goals. Expert systems are often used to analyze the solution space by reasoning on the basis of the available knowledge. These tools have played an important role in solving the site selection problem but have limits in dealing with all relevant criteria and reaching the most suitable solutions.

Recent developments in the field of decision making have led to dramatic improvements in the capabilities of GIS for industrial location analysis. These developments especially concern the analysis of attribute data and procedures for multicriteria analysis $[10,11]$. Unfortunately, MCDA methods assume normalized data, which is difficult to achieve in industrial location problems where it is necessary to compare several quantitative and qualitative criteria in a highly imprecise and uncertain environment [12]. To compare the various criteria in MCDA, data must be standardized to the appropriate range suitable for the analysis.

To address all of the above aspects in an integrated way, we propose a novel Comprehensive Method for Industrial Site Selection (CMISS), which provides an innovative approach to decision making that mitigates uncertainties in the input data by combining various complex interacting decision support systems in a synergic way. In order to achieve this goal, we developed an integrated approach based on an intelligent decision support system for the analysis of heterogeneous and noisy input data, a geographic information system for generating alternatives, and a spatial decision support system for the evaluation of alternatives.

To demonstrate the effectiveness of the proposed method, we present its application in a real case study, obtaining the same results suggested by experts in the field, which also correspond

R. Donida Labati and V. Piuri are affiliated with the Università degli Studi di Milano, Crema 26013, Italy (e-mail: ruggero.donida@unimi.it; vincenzo.piuri@unimi.it). 
to recent strategic choices performed by important international companies. To the best of our knowledge, this is the first study in the literature that aims to overcome the uncertainty of input data in decision support systems for industrial site selection.

This paper is organized as follows: In Section 2, we summarize the literature in the field of industrial site selection, highlighting the role of multi-criteria decision analysis and geographic information systems. In Section 3, we present the innovative Comprehensive Method for Industrial Site Selection. Section 4 presents the experimental validation of the methodology in the Vojvodina region of Serbia as a case study to show the implementation choices. Section 5 derives some conclusions and directions for future research.

\section{BACKGROUND}

Most authors dealing with industrial location or production network design do not discuss the planning process but focus solely on decision support models. When the planning process is considered, it is often in the context of locating a single plant, excluding network design considerations [13].

In the literature, the planning processes focused on locating a single site generally disaggregate the problem into several levels. Zelenovic [6] distinguishes macro- and micro-locations

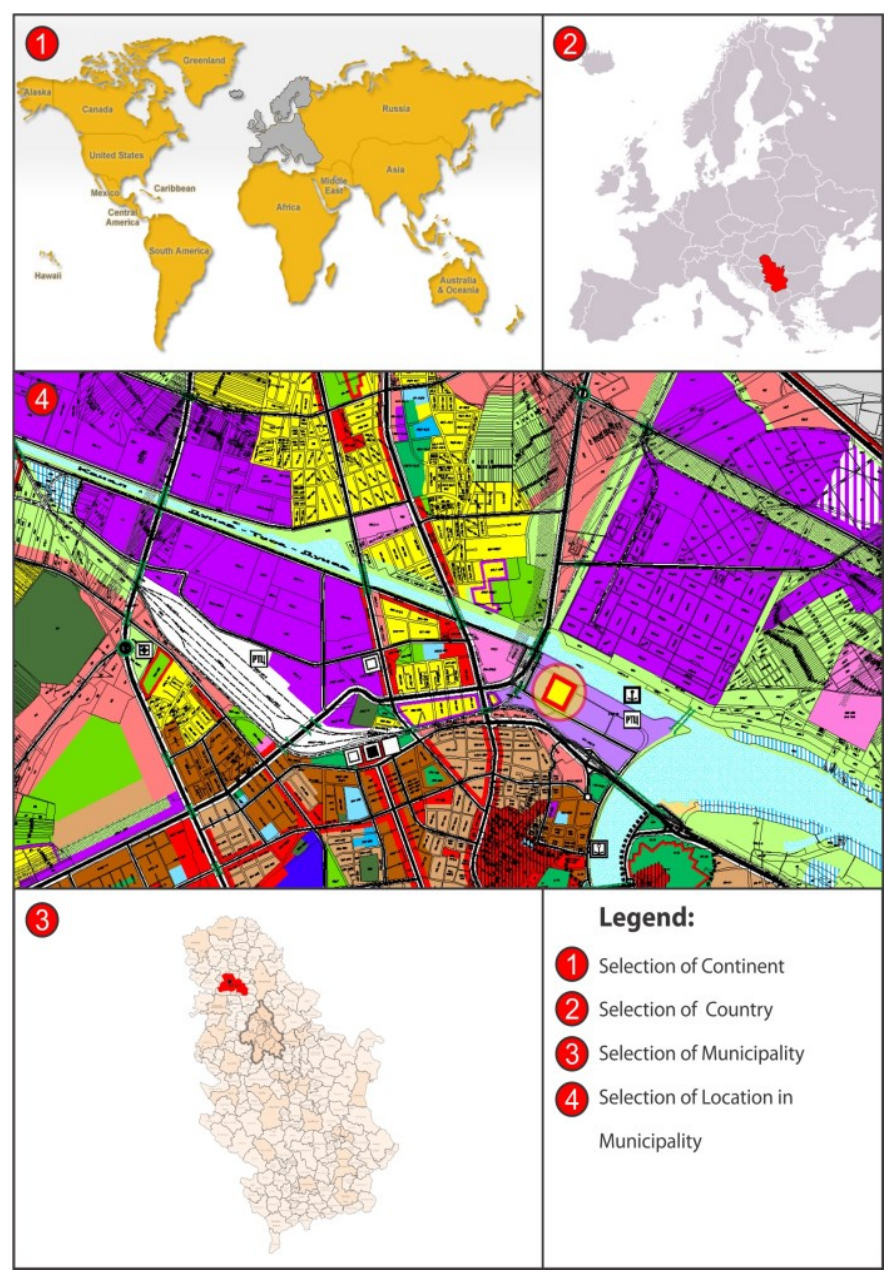

Fig. 1. Phases of the site selection process and proposes a process consisting of four phases involving the selection of the continent, the country, the municipality and finally the specific location in the municipality (see Fig. 1) [14].

Industrial site selection requires a multi-criteria decision analysis (MCDA) [15]. The term multi-criteria decision analysis applies to various methods that help decision makers in finding better solutions. Multi-criteria decision making (MCDM) problems can be classified on the basis of the major components of MCDA: multi-objective decision analysis (MODA) versus multi-attribute decision analysis (MCDA), individual versus group decision-maker problems, and decision under certainty versus decision under uncertainty. Multiattribute techniques are discrete methods because they assume that the number of alternatives is explicit. The multi-objective methods are mathematical programming, model-oriented techniques, in which the alternatives, identified by solving a multi-objective mathematical programming problem, must be generated [16]. According to Kenney [17], the two major approaches are the alternative-focus approach, which aims at generating the decision alternatives, and the value-focus approach, which uses the values (attributes) as a fundamental element in the decision analysis.

It has been estimated that $80 \%$ of the data used by managers and decision makers for industrial site selection are geographical (spatial) in nature [18]. Decision problems that involve geographical data are referred to as geographical or spatial decision problems [17]. Industrial site selection is one of these problems that require specific support for managing geolocated data. The spatial characteristics of industrial site selection require the use of geographic information systems in collecting and analyzing data.

Geographic information systems have been used to identify suitable areas for industry by using a multi-criteria evaluation method based on Boolean logic for producing suitability maps, map-based graphic representations showing how suitable each location is for the envisioned industry [19]. The Boolean method evaluates the area under analysis by using a grading scale $[0,1]$, where 0 denotes sites totally unsuitable for industry and 1 represents suitable sites. In recent industrial location research, the simple additive weighting (SAW) method was presented in a GIS environment [20] as an MCDA decision rule for evaluating location alternatives. The SAW method uses a weighted summation of criteria in which weights rank the land suitability for an industrial location.

The industrial location problem requires complex knowledge management and analysis. The need for an appropriate support for human decision makers is due to four types of limitations: cognitive, economic, time, and competitive demand [12]. Usually, previous experience or expert knowledge is used to design decision support systems [21]. For example, the intelligent approach proposed in [22] for industrial site selection based on GIS, expert systems (ES) and the Analytic Hierarchy Process (AHP) method divides the process into two phases: screening and evaluation. In the screening phase, the ES recommends suitability criteria and the GIS screens all candidate sites located in the region of interest. In the evaluation phase, the AHP is used, out of the GIS, to identify the most appropriate site by comparing alternative sites on the basis of 
copyrighted component of this work in other works. DOI: 10.1109/JSYST.2015.2444471

non-spatial attributes.

Unfortunately, the above approaches are not adequate for industrial site selection because they do not consider uncertainties in decision making. Management of uncertainty is, in fact, a very important issue in the design of a decision support system for the envisioned application because data may be non-defined, inaccurate, or ambiguous. Another challenge is bringing quantitative and qualitative data into the same analytic methodology. Industrial site selection must be performed efficiently, addressing all of the above aspects in a comprehensive, coordinated way.

\section{CMISS: A COMPREHENSIVE METHOD}

In this section, we introduce our innovative approach for making strategic decisions on industrial location, including consideration for data uncertainty: the Comprehensive Method for Industrial Site Selection (CMISS).

The proposed comprehensive method uses a coordinated set of interacting decision support systems: an intelligent decision support system for industrial location criteria analysis, a geographic information system for generating alternatives, and a spatial decision support system for alternatives evaluation. The developed intelligent decision support system for industrial location criteria analysis is a hierarchical environment, based on a fuzzy expert system, which uses a set of fuzzy inference systems (FIS) to interpret, standardize, and fuse heterogeneous data in order to estimate normalized industrial location criteria. The geographic information system (GIS) based on the spatial database created from the environmental analysis is used for mining data and generating alternatives in the screening process. The spatial decision support system is based on multicriteria decision analysis in the GIS environment, which uses the weighted linear combination (WLC) method [23] for evaluating and ranking the alternatives.

Because of the complexity of the selection process, we adopt the two-phase approach proposed in [6]: the selection of a macro-location (municipality) followed by the selection of a micro-location. These selections are made using our comprehensive methodology. In this paper, we focus only on the selection of the macro-location.

In CMISS, the decision-making process is divided into ten steps (see Fig. 2): A) Problem definition, B) Site selection criteria evaluation, C) Spatial database creation, D) Location alternatives generation, E) Fuzzy criteria analysis, F) Criteria suitability maps generation, G) Multi-criteria decision analysis, H) Final suitability map generation, I) Sensitivity analysis and $J$ ) Final recommendation generation. In the subsequent subsections, we analyze each of these steps.

\section{A. Problem definition}

The first step in all decision-making processes is to recognize and define the relevant characteristics of the decision problem. Depending on the business environment and the company's overall objectives, the problem definition specifies the essential inputs for the decision making process. Managers would like to have everything in one location: low labor costs and a quality workforce, simultaneously. These objectives are contradictory and very difficult to achieve. This problem can only be solved

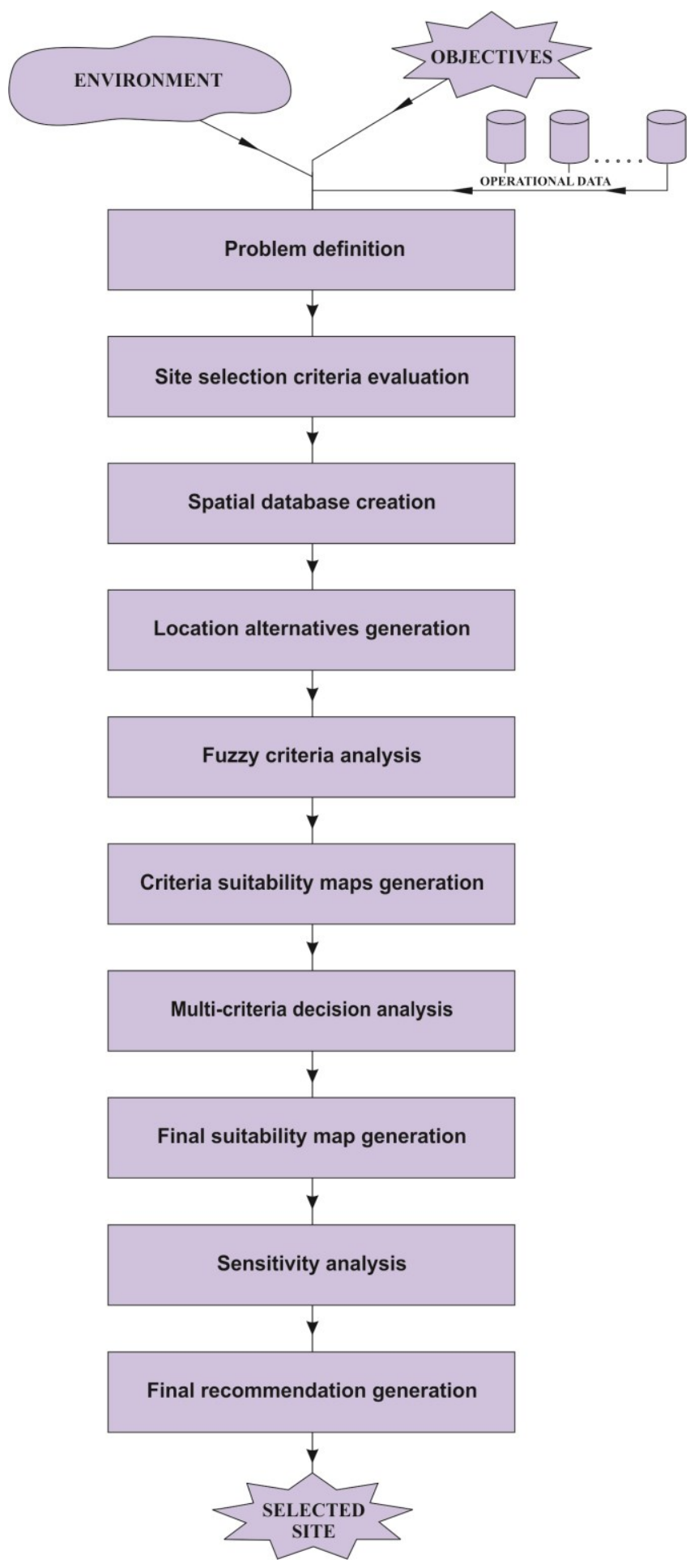

Fig. 2. The overall structure of the industrial site selection process in the Comprehensive Method for Industrial Site Selection (CMISS)

through compromise. Therefore, it is necessary to explain the problem and to find the space for compromise.

In this step, we define the main objectives that should not be in conflict and identify the decision makers (either an individual or a group) for the location problem under consideration. 
TABLE I

FACTORS OF IMPORTANCE FOR CHOOSING THE MUNICIPALITY (USAID RESEARCH IN SERBIA)

\begin{tabular}{ll}
\hline \hline No. & \multicolumn{1}{c}{ CRITERIA } \\
\hline 1. & Availability of a quality workforce \\
2. & Labor costs \\
3. & Geographic position of the municipality \\
4. & Transport infrastructure \\
5. & Availability of raw materials and intermediate goods \\
6. & Licensing and permitting procedures for the land \\
7. & Telecommunication infrastructure \\
8. & Reputation and efficiency of local authorities \\
9. & Availability and cost of business premises \\
10. & References from local partners and previous experience \\
11. & Availability of construction land \\
12. & Cost of construction land \\
13. & Level of political interference in business \\
14. & Incentives at the local level \\
15. & Ecology \\
16. & Utility costs \\
17. & Accommodations \\
\hline \hline
\end{tabular}

\section{B. The site selection criteria evaluation}

Once the decision problem is defined, CMISS evaluates the site selection criteria, i.e., location characteristics that influence the decision process for the envisioned case. A selection criterion may consist of either a single quantity observed in the analyzed environment or a group of quantities collectively defining the desired characteristics of the environment itself (in this second case, the criterion is obtained by merging the observed quantities into a single figure of merit). These criteria are stored as attributes associated with the specific location. In this step, criteria are analyzed according to a specific problem definition and ordered according to their relevance for the envisioned case.

For achieving an efficient site selection process, the set of considered criteria must be optimized: We need to choose only those criteria that actually affect the quality of the decision. This criteria reduction is critical because all subsequent steps rely on the correctness, accuracy, and completeness of the adopted set.

As an example for testing our comprehensive method, we adopted the criteria identified in USAID research [24] for the case study in Serbia (see Tab. 1).

\section{Spatial database creation}

The third step involves the creation of a spatial database that contains data for all of the selected criteria in the region of interest. For such a purpose, it is necessary to collect and store all data related to the decision problem, with specific reference to data related to the selected criteria. Spatial data collection includes GIS maps, satellite and aircraft images, and descriptive data related to the observed location. Geographic data are obtained by remote sensing, by entering existing data (statistics), by collecting data and geo-locating them with GPS, or by digitizing and scanning maps. Collected data should be first analyzed to ensure consistency and then stored. This step is the most demanding in terms of time and costs.

\section{Location alternatives generation}

This step focuses on generating decision alternatives by using the GIS in a screening process. By screening the geographic locations in the region of interest, we obtain the necessary information for the subsequent multi-criteria analysis, which requires clearly defined location alternatives for analysis. Each location alternative should be a feasible location for the industry and should meet the basic construction requirements. For mining data and generating the location alternatives, we developed a GIS by using ArcGIS [25] and the spatial database developed in step $C$.

\section{E. Fuzzy criteria analysis}

To provide a consistent framework for knowledge management under uncertainty, criteria analysis and standardization, we developed an intelligent decision support system for industrial location criteria analysis based on a set of fuzzy inference systems (FIS). FISs are methods that use fuzzy rules to map inputs to outputs.

Every FIS can be divided into three main components: the fuzzifier, the knowledge base, and the defuzzifier [26]. The fuzzifier and the defuzzifier convert external information into fuzzy sets and vice versa, respectively. The knowledge base consists of the set of rules that simulates the reasoning of human experts.

There are different approaches to FIS design and implementation. The Mamdani's fuzzy inference method [27] is the most commonly used in decision support systems [28]. This method is characterized by the following fuzzy rule schema: IF $x$ IS $A$ THEN $y$ IS $B$, where $A$ and $B$ are fuzzy sets defined on the input and output domains and $x$ and $y$ are the input and output fuzzy variables. If the antecedent contains several variables, they are joined by OR and AND operators.

FIS can be based on type-1 fuzzy sets or type- 2 fuzzy sets. In this work, we decided to use type-1 fuzzy systems due to their greater simplicity in design and customization. However, type2 fuzzy systems should be considered for future implementations because they permit a more robust modeling of uncertainty, for overcoming limitations typical of type-1 fuzzy systems.

A FIS has been designed and implemented for each of the criterion considered. Each FIS is used to interpret, standardize, and fuse the heterogeneous input data in order to estimate the values of the industrial location criteria, normalized in the range $[0,10]$. FISs have been implemented using the Matlab Fuzzy Logic Toolbox [27].

1) Fuzzification: For each fuzzy system, we used trapezoidal membership functions (MFs) for fuzzification of quantitative variables, while triangular membership functions were used for qualitative values [29]. We chose triangular and trapezoidal MFs because non-experts in fuzzy logic were able to perform their tuning in a more intuitive manner with respect to other widely used MFs (e.g., Gaussian and sigmoidal functions).

For each FIS, the number of used MFs and their shape are tuned for each possible application scenario according to the knowledge of human experts. For quantitative inputs, the fuzzification is based on 5 trapezoidal membership functions. For example, in the case distance to the airport the represented values are Very Close $(V C)$, Close $(C)$, Acceptable (A), Faraway and (F) Very Far Away (VF) (see Fig. 3a). For qualitative inputs the fuzzification is based on 4 membership functions (MFs) representing the linguistic properties. For example, in the case of ecology the represented values are Degraded environment (D), Endangered environment (E), 


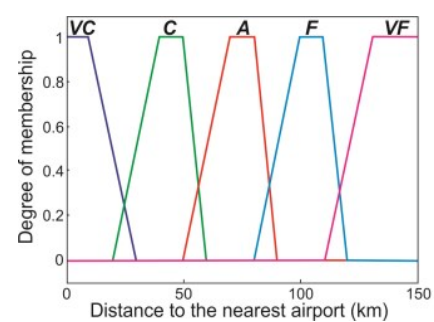

(a)

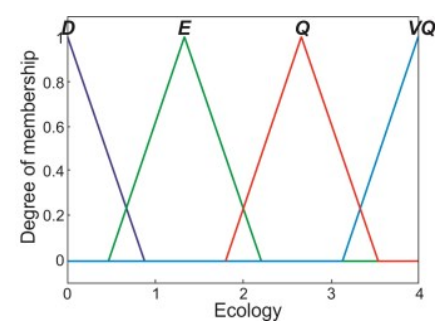

(b)
Fig. 3. Examples of the membership functions used by the proposed approach: (a) quantitative inputs; (b) qualitative inputs

Quality environment $(Q)$, and High quality environment (see Fig. 3b).

2) Knowledge base: Each FIS uses the fuzzy rules of the knowledge base for approximate reasoning. To create the knowledge base, a group of experts cooperated in defining a unique set of rules applicable to different cases of study.

As an example, we show the following criteria:

\section{Labor Cost}

To design the fuzzy inference system for the criterion labor cost, $y_{i}$, we used the input variable salary and benefits, $x_{i}$, evaluated in the location $i$. This quantitative input variable is in the range [200,500]. Linguistically, labor cost is represented by five trapezoidal membership functions: Very Low price (VL), Low price (L), Acceptable price (A), High price $(H)$ and Very High price $(V H)$. The knowledge base is therefore:

1. IF $x_{i}$ IS $V L$ THEN $y_{i}$ IS $E$

2. IF $x_{i}$ IS $L$ THEN $y_{i}$ IS $G$

3. IF $x_{i}$ IS $A$ THEN $y_{i}$ IS $S$

4. IF $x_{i}$ IS $H$ THEN $y_{i}$ IS $R$

5. IF $x_{i}$ IS $V H$ THEN $y_{i}$ IS $I$

Fig. 4 shows the output surface for the FIS labor cost.

\section{Road transportation}

To design the fuzzy inference system for the criterion road transportation, $y_{i}$, we used the input variable importance of road, $x_{i}$, evaluated in the location $i$. This quantitative input variable is defined in the range [1,4]. Linguistically, road transportation is represented by four triangular membership functions $1^{\text {st }}$ level $(1 L), 2^{\text {nd }}$ level $(2 L)$, $3^{\text {rd }}$ level $(3 L)$, and $4^{\text {th }}$ level ( $4 L)$, representing the level of importance from highest to lowest. The knowledge base is:

1. IF $x_{i}$ IS $1 L$ THEN $y_{i}$ IS $I$

2. IF $x_{i}$ IS $2 L$ THEN $y_{i}$ IS $S$

3. IF $x_{i}$ IS $3 L$ THEN $y_{i}$ IS $G$

4. IF $x_{i}$ IS $4 L$ THEN $y_{i}$ IS $E$

Fig. 5 shows the output surface for the FIS road traffic.

\section{Availability of quality workforce}

To design the fuzzy inference system for criterion availability of quality workforce, $y_{i}$, in the location $i$, we used four input variables: Faculty degree $\left(f_{i}\right)$, High school degree $\left(h_{i}\right)$, Elementary school and under $\left(e_{i}\right)$, Number of workforce $\left(w_{i}\right)$ and Unemployed people $\left(u_{i}\right)$. For the input variable Faculty degree, $f_{i}$, we defined the percentage range $[0,30]$. For the input variable High school degree, $h_{i}$, we defined the percentage range $[40,65]$. The input variable

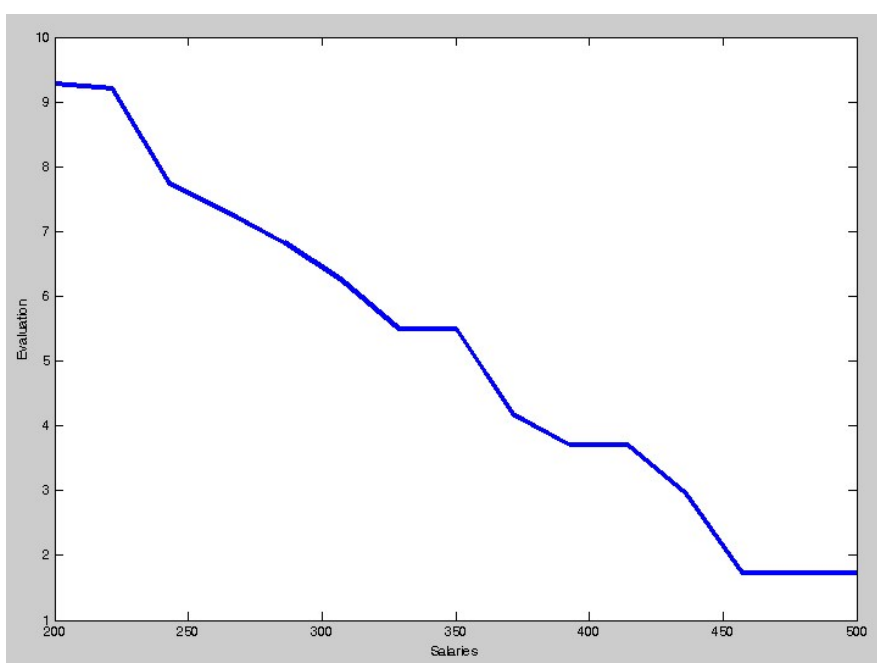

Fig. 4. Output function for the FIS labor cost

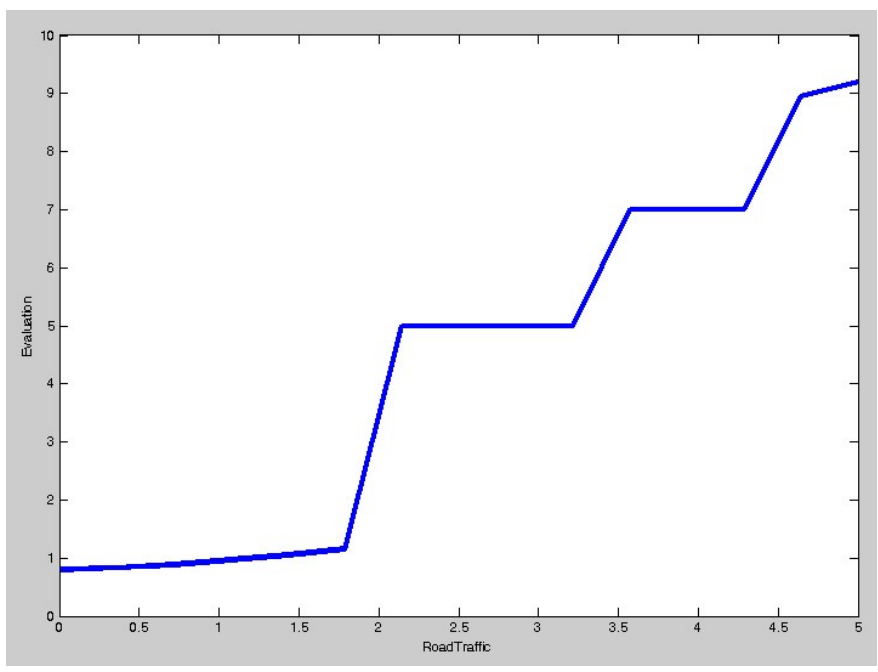

Fig. 5. Output function for the FIS road transportation

Elementary school and under, $e_{i}$, is in the percentage range $[20,55]$. The input variable Number of workforce, $w_{i}$, is in the range [5000,235000], and the input variable Unemployed people, $u_{i}$, is in the percentage range $[0,30]$. Linguistically, availability of quality workforce is represented by five trapezoidal membership functions: Very Small number (VS), Small number (S), Average number (A), High number (H), and Very High number (VH). The knowledge base is:

1. IF $f_{i}$ IS $V H$ OR $h_{i}$ IS $V H$ OR $e_{i}$ IS NOT $V H$ OR $w_{i}$ IS $V H$ OR $u_{i}$ IS $V H$ THEN $y_{i}$ IS $E$

2. IF $f_{i}$ IS $V H$ OR $h_{i}$ IS $V H$ OR $e_{i}$ IS NOT $H$ OR $w_{i}$ IS $V H$ OR $u_{i}$ IS $V H$ THEN $y_{i}$ IS $E$

3. IF $f_{i}$ IS $V H$ OR $h_{i}$ IS $V H$ OR $e_{i}$ IS NOT $A$ OR $w_{i}$ IS $V H$ OR $u_{i}$ IS $V H$ THEN $y_{i}$ IS $E$

4. IF $f_{i}$ IS $V H$ OR $h_{i}$ IS $V H$ OR $e_{i}$ IS $V S$ OR $w_{i}$ IS $V H$ OR $u_{i}$ IS $V H$ THEN $y_{i}$ IS $E$ 


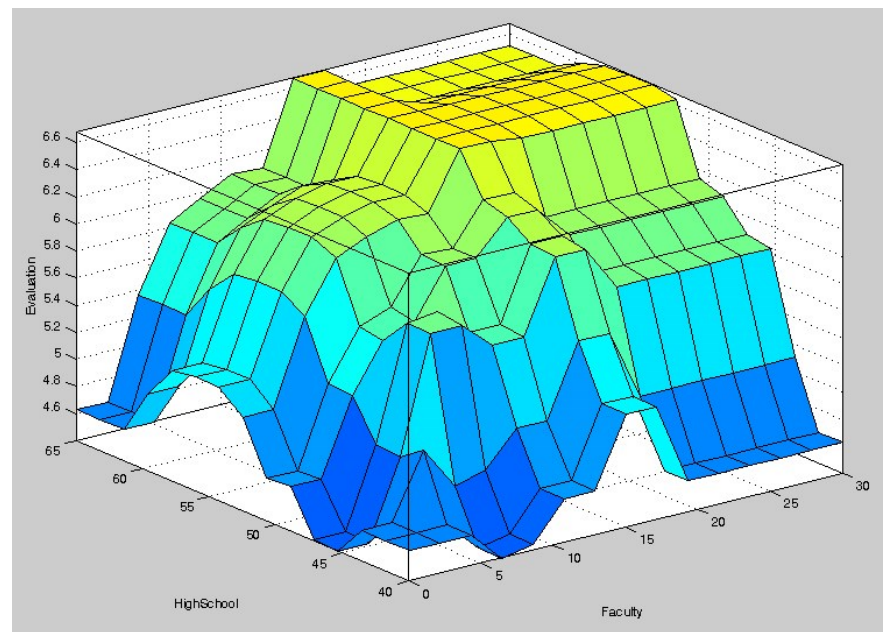

Fig. 6. Output function for the FIS availability of quality of workforce

5. $\quad$ IF $f_{i}$ IS $H$ OR $h_{i}$ IS $H$ OR $e_{i}$ IS $S$ OR $w_{i} H$ OR $u_{i}$ IS $H$ THEN $y_{i}$ IS $G$

6. IF $f_{i}$ IS $A$ OR $h_{i}$ IS $A$ OR $e_{i}$ IS $A$ OR $w_{i} A$ OR $u_{i}$ IS $A$ THEN $y_{i}$ IS $S$

7. IF $f_{i}$ IS $S$ OR $h_{i}$ IS $S$ OR $e_{i}$ IS $H$ OR $w_{i} S$ OR $u_{i}$ IS $S$ THEN $y_{i}$ IS $R$

8. $\quad$ IF $f_{i}$ IS $V S$ OR $h_{i}$ IS $V S$ OR $e_{i}$ IS $V H$ OR $w_{i} V S$ OR $u_{i}$ IS $V S$ THEN $y_{i}$ IS $I$

Fig. 6 shows the output surface for the FIS availability of quality workforce.

3) Defuzzification: The defuzzification process is based on the "centroid" rule [29] and is used to derive the final quantitative output. The output of the system is defined by the MFs shown in Fig. 7. They include five triangular trapezoidal membership functions representing the linguistic properties: Insufficient (I), Regular (R), Satisfactory (S), Good (G), and Excellent (E), which were defined by the experts according to their actual decision-making strategy.

\section{F. Criteria suitability maps generation}

To support an effective analysis of each criterion, we adopt suitability maps [30], which enable visual thinking and spatial data mining. To produce the suitability maps, the normalized and fused data of each criterion are evaluated for each alternative. For assigning this information to alternatives, we used the join function in ArcGIS [25]. Then, we applied a color ramp to the criterion values. The most common usage of the color ramp is from green (maximum suitability=10) to red (minimum suitability $=0$ ). This colored view allows decision makers to achieve effective understanding of the location characteristics. In this way, possible hidden patterns can be easily seen and used in decision making.

\section{G. Multi-criteria decision analysis}

The multi-criteria decision analysis is performed in three phases:

1) definition of the criteria weights,

2) estimation of the consistency ratio,

3) evaluation and ranking of the location alternatives.

To determine the criteria weights in the first phase, we used the Analytical Hierarchy Process (AHP), a pairwise comparison technique developed by Saaty to identify the relative relevance of criteria [31]. This analysis produces a pairwise comparison matrix ranking criteria from those of extreme importance (9) to those of equal importance (1). The computation of the criteria weights is then performed by applying the following procedure:

- for each column of the comparison matrix, compute the column total by adding the criterion score of each element of the column;

- divide each element in every column of the matrix by the corresponding column total;

- compute the weight of the criterion associated with a row of the comparison matrix by averaging the scores of that row.

In the second phase, the consistency of the obtained criteria weights should be analyzed. Decision makers are, in fact, rarely consistent in estimating these weights in pairwise comparisons. We first evaluate the Consistency Vector, $\lambda$, by multiplying the pairwise comparison matrix by the vector of the criteria weights. The Consistency Index, CI, of the envisioned pairwise comparison matrix is defined as:

$$
C I=\frac{\lambda_{\max }-n}{n-1}
$$

where $\lambda_{\max }$ is the average value of the consistency vector and $n$ is the number of criteria. We then consider the Random Index, $R I$, as the consistency index of a randomly generated pairwise comparison matrix [31]. The random index provides a reference for consistency when the comparison matrix is created without any agreement between decision makers on criteria weights.

The Consistency Ratio, $C R$, measures the agreement among the decision makers, i.e., how much the pairwise comparison matrix ratings were randomly generated instead of being based on an objective, shared view of criteria among decision makers. The consistency ratio is defined as:

$$
C R=\frac{C I}{R I}
$$

A consistency ratio greater than 0.10 means that there is insufficient agreement among decision makers on the criteria weights and that, therefore, the pairwise comparisons should be re-discussed [31].

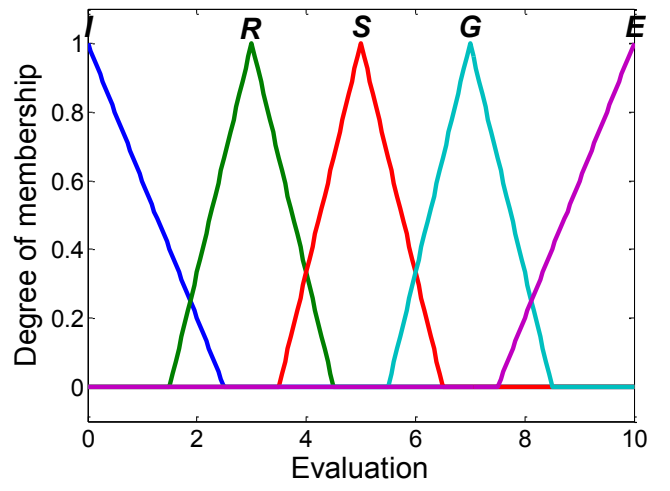

Fig. 7. Membership functions used by the FIS defuzzification module

For evaluating and ranking the location alternatives in the third phase, we used the Weighted Linear Combination (WLC) 
method [23] in the GIS environment as decision rule for the multi-criteria decision analysis. The Suitability, $S$, for each location alternative is obtained by multiplying the criteria weight, $w_{i}$, and criteria value, $x_{i}$, for each criterion $i$ and then summing the products over all criteria:

$$
S=\sum w_{i} x_{i}
$$

This phase was implemented by using MCDA4ArcMap [32], an open source multi-criteria tool for ArcGIS, in order to calculate suitability for all location alternatives.

\section{H. Criteria suitability map generation}

The final suitability map represents the output values from the multi-criteria decision analysis. These outputs are expressed in the range [0,1] and presented in the final suitability map [32]. For visual representation, we adopted the same color ramp that has been used in subsection $F$ for graphic visualization.

\section{Sensitivity analysis}

The sensitivity analysis tests how much the sensitivity map and, therefore, our decisions are sensitive to criteria variations. Thus, in the sensitivity analysis, we test the accuracy and the robustness of the multi-criteria analysis. This allows decision makers to be confident in their choices even though the values of the criteria may not be highly accurate. The most important elements to consider in the sensitivity analysis are the criteria weights and the criteria values. Sensitivity of criteria weights is often more important because they are essential in value judgments and are rather subjective (decision makers may disagree on them, more than on other parameters).

The proposed sensitivity analysis is based on adding and subtracting $5 \%$ of the current values [30] in two separate tests:

$$
\begin{array}{ll}
\text { Sensitivity analysis } 1: & w_{1}=x \cdot 0,95 ; w_{2}=x \cdot 1,05 \\
\text { Sensitivity analysis } 2: & w_{1}=x \cdot 1,05 ; w_{2}=x \cdot 0,95
\end{array}
$$

After the sensitivity analysis, if the ranking of the location alternatives remains the same, we assume that the results of the multi-criteria decision analysis are sufficiently robust. Otherwise, it is necessary to redefine the criteria weights and perform a new sensitivity analysis in order to confirm the ranking of the location alternatives.

\section{J. Final recommendation generation}

The last step of the site selection process is the identification of the most suitable site (municipality) on the basis of the performed multi-criteria analysis. The best location is the one that has the highest score, i.e., the brightest green color.

\section{CASE STUDY}

In this section, we describe an experimental application of the proposed comprehensive method for industrial site selection, which has been described in Section 3. To demonstrate the efficiency and the effectiveness of the proposed approach, we show its use in a case in the Vojvodina region of Serbia. In the presented example, the location problem has been defined for siting an Automotive Component Part Manufacturer. The main desired objectives of the selection process were low operational cost, good geographic position, good quality transportation infrastructure, and a businessfriendly location (municipality).

The starting point for the site selection criteria in this test case is shown in Table 1 [24]. For this case study, we focused on fifteen criteria: Availability of quality workforce, Labor cost, Geographic position of municipality, Road transportation, Railway transportation, Water transportation, Air transportation, Telecommunication infrastructure, Availability of raw materials and intermediate goods, Reputation and efficiency of local authorities, Availability of construction land, Cost of construction land, Ecology, Utility costs, and Accommodations. Transport infrastructure is split into road transportation, rail transportation, water transportation, and air transportation for better understanding and analysis of its impact.

In the screening process, we obtained 45 alternatives (municipalities) in Vojvodina to be used in the selection of the most appropriate site. Fig. 8 shows the locations of the alternatives and the infrastructure potential in the region of interest. By analyzing the geographic position of Vojvodina in Europe from the point of view of access to the markets of the automotive industry, we found a large number of manufacturers within a $1000 \mathrm{~km}$ distance.

Using our fuzzy expert system, we evaluated the criteria for each municipality, and we derived the corresponding suitability as industrial location, considering all fifteen criteria.

The standardized evaluation of all criteria was performed for each of the 45 municipalities of the case study. The suitability maps were generated (see Fig. 9) with normalized values.

The multi-criteria decision analysis was performed. In the first phase, experts in the field evaluated the criteria weights using the AHP method. In the second phase, the consistency of the obtained criteria weights was evaluated $(\mathrm{CR}=0.052346)$ and verified to satisfy the condition $\mathrm{CR}<0.10$. In the third and the fourth steps, we evaluated and ranked the alternatives by using the WLC method as decision rule (see Table 2).

To test the robustness and the sensitivity of the multi-criteria decision analysis, we slightly perturbed the criteria weights by introducing what the experts in the field consider to be typical errors in evaluating the criteria, i.e., we changed the criteria by $\pm 5 \%$. The results show that the ranking remains unaffected by these changes. This means that small errors (less than 5\%) in the estimation of criteria weights can be considered negligible. In further analysis, we randomly changed criteria weights by $\pm 10 \%$. The results show that the main ranking (the first five results) remains unaffected by these changes. Other results are affected, with small changes in the final rank linearly, which can be considered negligible for the final decision.

Based on the MCDA results, we produced the final suitability map using the color ramp from red to green (see Fig. 10), where red represents low suitability and green represents high suitability of alternatives (municipalities).

According to this comprehensive analysis, we finally recommend that the municipality with the highest suitability (Indjija) is the most appropriate site for the Automotive Component Part Manufacturer in the region of Vojvodina. Experiments have shown that the proposed approach obtains 


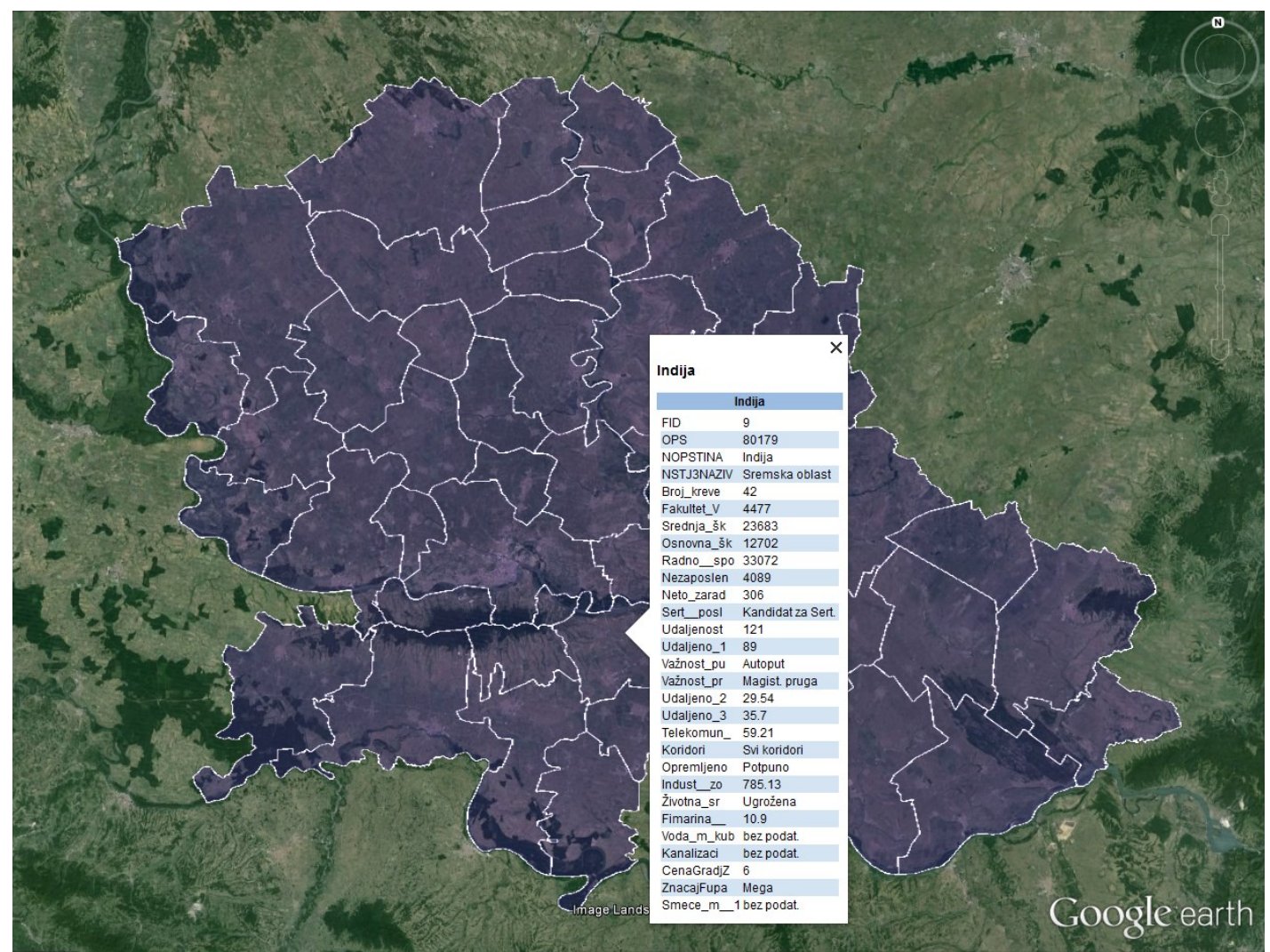

(a)

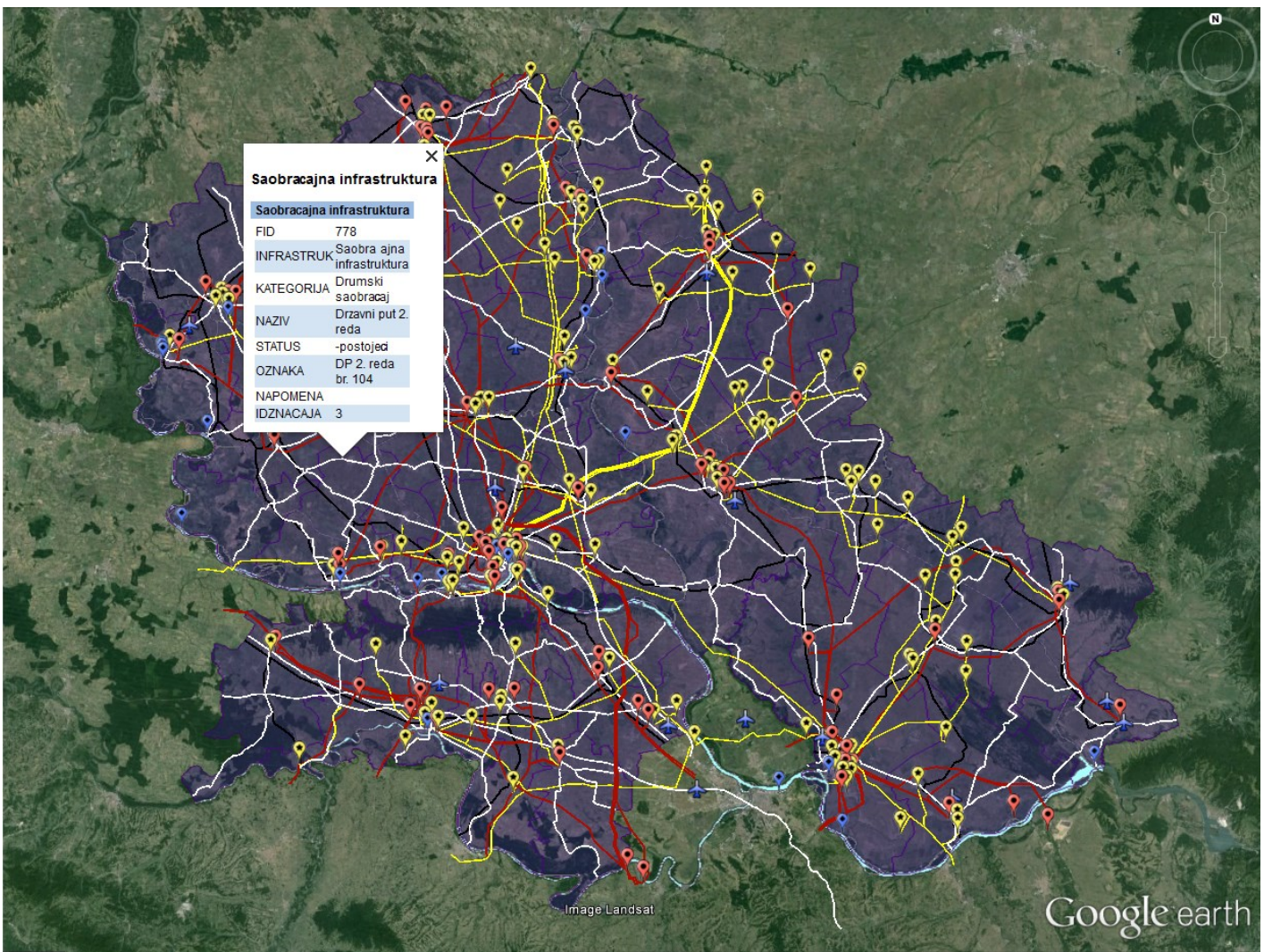

(b)

Fig. 8. Screening process: (a) generating location alternatives; (b) infrastructure potentials 


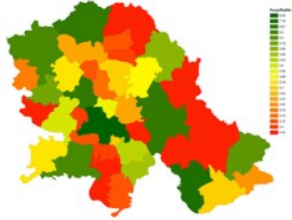

1) Availability of quality workforce

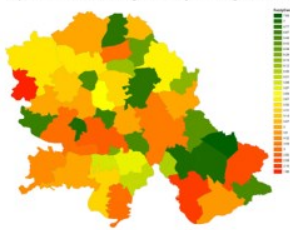

2) Labor cost

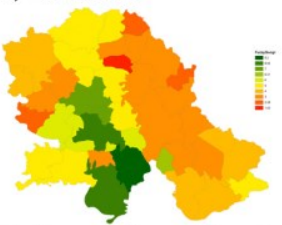

3) Geographic position of municipality

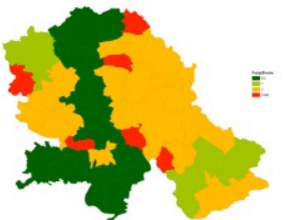

4) Road transportation

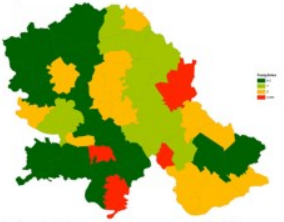

5) Railway transportation

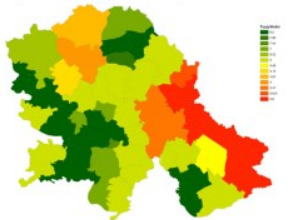

6) Water transportation

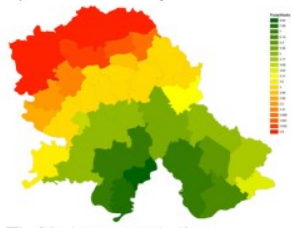

7) Air transportation

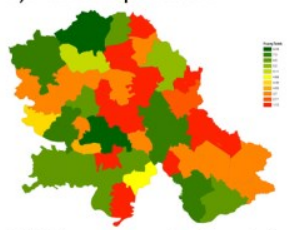

8) Telecommunication infrastructure

Fig. 9. Criteria suitability maps for 1) Availability of quality workforce; 2) Labor cost; 3) Geographic position of municipality; 4) Road transportation 5) Railway transportation; 6) Water transportation; 7) Air transportation; 8) Telecommunication infrastructure; 9) Availability of raw materials and intermediate goods; 10) Reputation and efficiency of local authorities; 11) Availability of construction land; 12) Cost of construction land; 13) Ecology; 14) Utility costs, and 15) Accommodations
TABLE II LOCATION ALTERNATIVES SUITABILITY

\begin{tabular}{|c|c|c|}
\hline Numb. & MUNICIPALITY & WLC Result \\
\hline 1. & Indija & 0.802 \\
\hline 2. & Stara Pazova & 0.760 \\
\hline 3. & Sremska Mitrovica & 0.706 \\
\hline 4. & Ruma & 0.696 \\
\hline 5. & Novi Sad & 0.677 \\
\hline 6. & Vrbas & 0.650 \\
\hline 7. & Temerin & 0.636 \\
\hline 8. & Kovačica & 0.632 \\
\hline 9. & Alibunar & 0.624 \\
\hline 10. & Sombor & 0.619 \\
\hline 11. & Subotica & 0.609 \\
\hline 12. & Sremski karlovci & 0.604 \\
\hline 13. & Bela Crkva & 0.585 \\
\hline 14. & Zrenjanin & 0.583 \\
\hline 15. & Mali Idoš & 0.581 \\
\hline 16. & Pančevo & 0.578 \\
\hline 17. & Bački Petrovac & 0.578 \\
\hline 18. & Kovin & 0.574 \\
\hline 19. & Bačka Topola & 0.574 \\
\hline 20. & Srbobran & 0.567 \\
\hline 21. & Kanjiža & 0.558 \\
\hline 22. & Odžaci & 0.557 \\
\hline 23. & Vršac & 0.551 \\
\hline 24. & Plandište & 0.550 \\
\hline 25. & Kikinda & 0.547 \\
\hline 26. & Novi Bečej & 0.545 \\
\hline 27. & Bečej & 0.536 \\
\hline 28. & Titel & 0.536 \\
\hline 29. & Šid & 0.533 \\
\hline 30. & Irig & 0.530 \\
\hline 31. & Žabalj & 0.519 \\
\hline 32. & Bačka Palanka & 0.508 \\
\hline 33. & Pećinci & 0.504 \\
\hline 34. & Kula & 0.498 \\
\hline 35. & Čoka & 0.491 \\
\hline 36. & Bač & 0.491 \\
\hline 37. & Sečanj & 0.489 \\
\hline 38. & Opovo & 0.484 \\
\hline 39. & Senta & 0.461 \\
\hline 40. & Žitište & 0.446 \\
\hline 41. & Beočin & 0.441 \\
\hline 42. & Nova Crnja & 0.429 \\
\hline 43. & Ada & 0.428 \\
\hline 44. & Apatin & 0.399 \\
\hline 45. & Novi Kneževac & 0.381 \\
\hline
\end{tabular}

accurate results in the region of interest, coinciding with the choices of senior expert analysts. In the past ten years important international companies (Grundfos, Henkel, Terraproduction, IGB Automotive, I.G. Bauerhin Gmbh, etc.) have chosen Indjija municipality for their new greenfield investment and have invested more than half a billion euros. All these facts corroborate the results of the proposed methodology, confirming that CMISS efficiently provides the most suitable solution.

\section{CONCLUSIONS}

This paper proposed an innovative Comprehensive Method for Industrial Site Selection (CMISS). Specifically, we focused on the macro-location analysis (municipality level): from the analysis of the environment to the evaluation of the relevant 


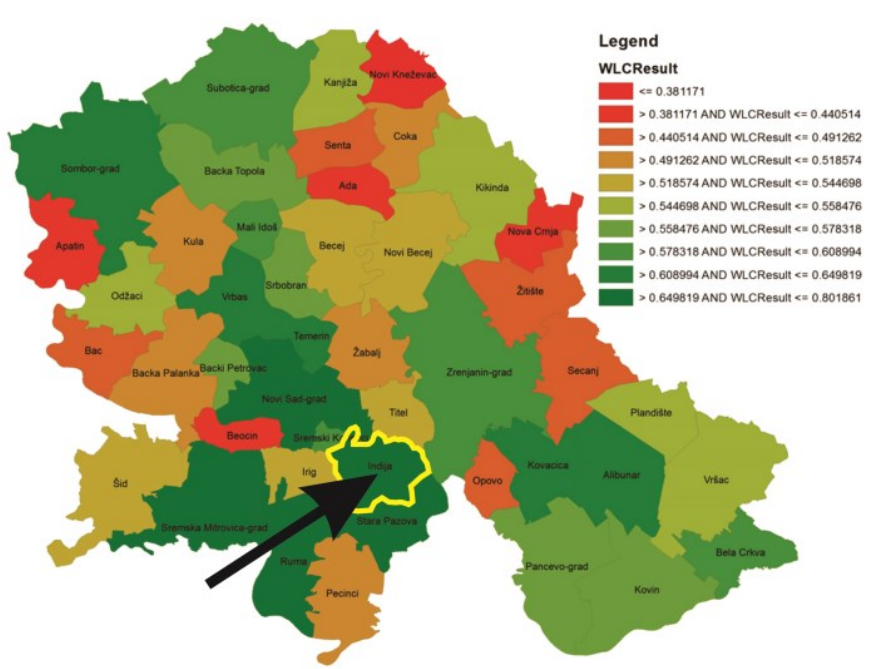

Fig. 10. Final suitability map

characteristics (criteria), from the identification of the location alternatives to their characterization, and from their competitive analysis to the location selection.

The proposed comprehensive method uses a set of interacting decision support systems: a geographic information system for collecting spatial characteristics and generating alternatives, a complex intelligent decision support system for industrial location criteria analysis, and a spatial decision support system for the evaluation of location alternatives. We used a GIS for data collection, spatial analysis, alternatives generation, and the production of suitability maps. We presented the innovative approach in this application field to manage uncertainty and incomplete information by using a fuzzy expert system. The expert system adopted is based on a set of Fuzzy Inference Systems (FIS) used to interpret, standardize, and fuse heterogeneous data in order to estimate the normalized industrial location criteria. The spatial decision support system for alternatives evaluation is based on MCDA in the GIS and uses the weighted linear combination (WLC) method for evaluating and ranking the location alternatives and generating the final suitability map. Results have been shown to be equivalent to those derived by experts in the field. The municipality with the highest suitability (Indjija) is the most appropriate selection.

In further research, the comprehensive method for industrial site selection will be studied at the micro-location level by analyzing the specific sites in the municipality identified by the macro-location analysis. Moreover, we will evaluate strategies to improve the robustness of the decision support system, such as the use of machine learning techniques for tuning the parameters of the fuzzy inference systems and the use of type2 fuzzy sets to represent the knowledge of each expert in a distinct manner.

\section{REFERENCES}

[1] R.L. Keeney, Siting Energy Facilities. New York: Academic Press, 1980.

[2] E.A. Williams and A.K. Massa. Siting of Major Facilities: A Practical Approach. New York: McGraw- Hill Inc., 1983.

[3] J.R. Eastman, H. Jiang, J. Toledano, "Multi-criteria and multi-objective decision making for land allocation using GIS," Multi attributes Analysis for Land-Use Management Environment \& Management, Vol. 9, pp. 227251, 1995.

[4] S.J. Carver, "Integrating Multi-Criteria Evaluation with Geo-graphical Information Systems," International journal of Geographic al Informati on Systems, 5 (3), pp.321-339, 1991.

[5] U. Bankhofer. Industrial Location Management. Wiesbaden, "Integrating Multi-Criteria Evaluation with Geo-graphical Information Systems," International journal of Geographic al Information Systems, 5 (3), pp.321339, 1991.

[6] D. Zelenovic, "Location of production systems," in The Design of Production Systems, 2nd ed. Novi Sad: Faculty of Technical Sciences, 2003, pp. 373-394.

[7] R.L. Church, "Geographical information systems and location science," Computers \& Operations Research 29, pp. 541-562, 2002.

[8] M. Badri, "Combining the Analytic Hierarchy Process and Goal Programming for Global Facility Location- Allocation Problem”, Int. J. Production Economics, 62, pp. 237-248, 1999.

[9] F. Witlox, "MATISSE: a relational expert system for industrial site selection," Expert Systems with Applications 24, pp. 133-144, 2003.

[10] J. Malczewski, "On the use of weighted linear combination method in GIS: common and best practice approaches, "Transactions in GIS, 4, pp. $5-22,2000$.

[11] J. Malczewski, C. Rinner, "Exploring multicriteria decision strategies in GIS with linguistic quantifiers: A case study of residential quality evaluation," Journal of Geographic Systems 7, pp. 249-268, 2005.

[12] M. Reisi, L. Aye, A. Soffianian, "Industrial site selection by GIS in Isfahan," 19th Iran International Conference on Geoinformatics, 2011.

[13] R. Hubner, "Production Network Design and Specialty Chemicals," in Strategic Supply Chain Management in Process Industries An Application to Specialty Chemicals Production Network Design. Berlin, Heidelberg, New York: Springer, 2007.

[14] Aleksandar Rikalović, Đorđe Ćosić, Srđan Popov, Đorđe Lazarević, "Spatial Multi-Criteria Decision Analysis for Industrial Site Selection: The State of the Art," XI Balkan Conference on Operational Research BALCOR, Vol. 11, pp.159-168, 2013.

[15] W. Atthirawong and B. MacCarthy, "An application of analytical hierarchy process to international location decision making," presented at 7th Annual Cambridge International Manufacturing Symposium: Restructuring Global Manufacturing, Cambridge. England: University of Cambridge, pp. 1-18, 2002.

[16] Renewable and Sustainable Energy Reviews, vol. 11, pp. 1584-1595, 2007 ,

[17] R.L. Keeney Value-focused thinking: a path to creative decision making. MA: Harvard University Press, Cambridge, 1992.

[18] J.R. Eastman, "Multi-criteria evaluation and GIS," Geographical information systems Vol. 1, pp.493-502, 1999.

[19] M. Reisi, L. Aye, A. Soffianian, "Industrial site selection by GIS in Isfahan," 19th Iran International Conference on Geoinformatics, 2011.

[20] S. Charungthanakij and S. Sarapirome, "Land suitability assessment for industrial location development using MCDA." In The 31st Asian Conference on Remote Sensing, pp. 1-5, 2010.

[21] C. W. Holsapple and A. B. Whinston, Decision Support Systems: A Knowledge Based Approach, West Publishing Company, Minneapolis, 1996.

[22] K. Eldrandly, N. Eldin, D. Sui. "A COM-based Spatial Decision Support System for Industrial Site Selection," Journal of Geographic Information and Decision Analysis, Vol. 7, No. 2, pp.72 -92, 2003.

[23] Drobne S., Lisec A., Multi-attribute Decision Analysis in GIS: Weighted Linear Combination and Ordered Weighted Averaging, Informatica 33, pp. 459-474, 2009.

[24] "Investment climate in Serbia-Investors' Perspective," Strategic Marketing Research, USAID, Municipal Economic Growth Activity, 2008.

[25] J. McCoy, K. Johnston, "Using ArcGIS Spatial Analyst", Environmental Systems Research InstituteI, Redlands, 2001.

[26] E. Czogala and J. Leski, Fuzzy and Neuro-Fuzzy Intelligent Systems, ser. Studies in Fuzziness and Soft Computing. Springer, vol. 47, 2000.

[27] Amindousta, S. Ahmeda, A. Saghafiniab, A. Bahreininejada, Sustainable supplier selection: A ranking model based on fuzzy inference system, Applied Soft Computing Vol. 12, No. 6, pp.1668-1677, 2012.

[28] R. Abrahart, L. See, and D. Solomatine, Building decision support systems based on fuzzy inference, in Practical Hydroinformatics, ser. Water Science and Technology Library, Eds., vol. 68, pp. 215 - 228, 2008. 
copyrighted component of this work in other works. DOI: 10.1109/JSYST.2015.2444471

[29] E. Mamdani and S. Assilian, "An experiment in linguistic synthesis with a fuzzy logic controller," Int. Journ. Man-Machine Studies, vol. 7, no. 1, pp. $1-13,1975$.

[30] J. Malczewski, GIS and Multicriteria Decision Analysis. New York: John Wiley \& Sons. 1999.

[31] T.L. Saaty, "A Scaling Method for Priorities in Hierarchical Structures," J. Math. Psychology, 15, pp. 234-281, 1977.

[32] C. Rinner, S. Voss, "MCDA4ArcMap - An Open-Source Multi-Criteria Decision Analysis and Geovisualization Tool for ArcGIS 10," Feature Article, Cartouche, Newsletter of the Canadian Cartographic Association, Number 86, Winter/Spring, pp.12-13, 2013. 